\title{
Learning performance improving on entrepreneurship training of higher education
}

\author{
Wan, Xiaojie \\ Wenzhou Business College \\ Human Resources Department, Chashan University Town \\ Wenzhou, Zhejiang Province, China \\ +8613757729931,0086-577-86597999,E-mail: 55183739@qq.com
}

\begin{abstract}
Consider the personality traits, the aim of this study is to identify mediation factors to decrease the affecting of personality traits when improving the entrepreneurship training of higher education. Actually, different personality traits among students are always existing. Consider different learning responding may cause performance variations. Therefore, develop an effective entrepreneurship training program to guide students of different personality traits for studying entrepreneurship, that has become a priority work on entrepreneurship education. For this reason, we should consider different personality traits and further try to decrease the affecting of personality traits. Existing studies have provided a more valuable training program. Based on the above, this study will identify different mediation factors based on personality traits, and further explore which mediation factors have a positive effect to decrease the affecting personality traits, and further help improve learning performance on entrepreneurship education of higher education.
\end{abstract}

Key words: innovation and entrepreneurship, trainging program, personality traits, higher education

\section{Introduction}

The innovation and entrepreneurship education of college students is one of the important ways to promote the smooth employment of college students and realize their self-worth [1-5]. To strengthen the "double creation" education of college students, it is necessary to cultivate complex talents with both knowledge professional knowledge and innovation and entrepreneurship ability. To build a system of innovation and entrepreneurship education for college students, we need to interact on multiple levels and in multiple dimensions, including fostering the spirit and ability of innovation, learning professional knowledge and knowledge and skills of innovation and entrepreneurship, building platforms, and providing incentives and financial support. Improve the ability of college students to innovate and start a business. In the "double innovation" education system, the cultivation of spirit and ability is the foundation, the learning of professional knowledge and innovation and entrepreneurship knowledge and skills is the ability, the establishment of a double innovation platform is an important way of self-realization, and the development of a double creation competition is the test. Incentive policies and financial support are helpful [6-8].

However, the University's great investment in entrepreneurship education has not significantly increased the entrepreneurial rate of college students [9-10], the mainly reason may be the training program of entrepreneurship lacks to consider for personality traits of students. For this reason, this study is to identify for mediation factors to decrease the affecting of personality traits, and further ensure the learning performance improving on entrepreneurship training program.

\section{Literature Review}

It is an important part of a series of strategic measures to build an innovative country. [11] put forward the concept of "public entrepreneurship and innovation" in the government's work report, carried out innovation and entrepreneurship education, vigorously cultivated the ability of college students to innovate and start their own businesses and sent a group of new young people with innovative thinking to the society. It is in line with the development strategy of science and education to rejuvenate the country and build an innovative country.

To carry out innovation and entrepreneurship education, more colleges fully recognizes and grasps the opportunities and challenges brought about by the development of the Internet, integrates resources inside and outside the school and various favorable resources online and offline, innovates teaching models, and comprehensively constructs an international, personalized and open environment for educating people. Under the current background of the times, our school has actively promoted innovation and entrepreneurship education through the establishment of innovative entrepreneurship education platforms at the school and hospital levels, as well as various laboratories such as teaching and scientific research, and relying on practical education in practical training outside the school. We will build an innovation and entrepreneurship alliance and build a platform for innovation and entrepreneurship education. It has also actively built a space for "innovation", created an atmosphere of "creation", built an "entrepreneurial incubator", stimulated students 'enthusiasm for entrepreneurship, and provided students with entrepreneurial intentions with maximum communication and development platforms and entrepreneurial services.

At present, entrepreneurship education in China has gradually changed from scattered and random education to systematic education. We need to change the concept of entrepreneurship guidance education, define the overall goal of entrepreneurship guidance education, and stratify the goals. We need to strengthen the building of a team of entrepreneurship guidance teachers, create an online classroom teaching model, and build a platform for entrepreneurship guidance for college students. In general, the way in which college students receive entrepreneurial education can 
basically be divided into two categories: First, systematic learning, which refers to formal and systematic entrepreneurial training provided by entrepreneurial colleges or business schools; The second is non-systematic training, that is, the way entrepreneurship courses, lectures and entrepreneurship competitions are held. Therefore, in the measurement of entrepreneurship education, we mainly list two types of indicators: systematic learning and non-systematic training.

[12] first examined the dimensions of entrepreneurship self-efficacy. According to the task function of entrepreneurship, he divides the self-efficacy of entrepreneurship into five dimensions: marketing, innovation, management, risk taking, and financial control. Based on core entrepreneurial skills, [13] identified six dimensions: risk and uncertainty management, innovation and product development, interpersonal and network management, opportunity recognition, access and allocation of key resources, and the creation and maintenance of an innovative work environment. Through the comparison of scales in Chinese, Indonesian, Japanese and Korean research literature, schwarzer et al. put forward four dimensions: the sense of opportunity recognition, the sense of relationship, the sense of management, and the sense of risk tolerance. According to the characteristics of the task to be accomplished in the process of entrepreneurship, Tangming, a Chinese scholar, proposed that the sense of self-efficacy of entrepreneurship be divided into five dimensions: innovation, opportunity recognition, risk assumption, relationship coordination and organizational commitment. Hanlizheng and Fuhong compiled a self-efficacy scale for college students. Including the basic ability effectiveness scale (six factors: entrepreneurial self-confidence effectiveness, entrepreneurial goal achievement effectiveness, leadership ability, interpersonal coordination and cooperation ability effectiveness, innovation ability effectiveness, learning ability effectiveness) and control effectiveness The scale (three Factors: lack of will, lack of ability, self-doubt, effectiveness). From the above literature, there is no recognized self-efficacy scale for entrepreneurship.

\section{Methodology}

\section{A. Research Design}

This paper was studied by means of questionnaire and expert interview, and the corresponding conclusions were drawn.

\section{$B$. research technique}

According to the characteristics of college students, we designed and distributed the questionnaire by combing the previous scale. The questionnaire covered four variables used to measure entrepreneurial self-efficacy: risk and uncertainty management, interpersonal and network management, opportunity recognition, and the creation and maintenance of an innovative work environment. The four variables are measured using 17 terms (including reverse terms). And through the "decision-making, finance, knowledge, learning" and other aspects, they have always measured and verified the individual's entrepreneurial self-efficacy from the positive and negative sides.

The measurement form adopts the 5-point system. In this study, 500 college students were selected to complete the questionnaire to test the reliability and validity of the questionnaire. The index coefficient of reliability test is higher than 0.7 , which shows that there is good internal consistency and accuracy among the variables. We use structural equation software to process 500 questionnaire data, calculate the corresponding relationship between each item and its corresponding variables, and simplify the scale.

In order to test the role of both sexes in regulating entrepreneurship education, entrepreneurial intentions and entrepreneurial competence, the samples were reclassified by gender and the differences in the regulatory roles between the male and female samples were compared. For this reason, we use the correlation coefficient matrix structure analysis method in structural equations. We use a female sample as a reference sample. With the help of the software, we calculate the correlation coefficient matrix between the measurement coefficients under the sex classification sample, and the value of each item for the sum analysis. This means that there are significant differences between male and female students in terms of entrepreneurship among university students. By comparison, male students are more likely than female students to receive more entrepreneurial education, have stronger entrepreneurial intentions and have more entrepreneurial competence.

In the same way, we measured and analyzed whether college students had a family background. We used whether there were relatives in the college family who had started a business as a basis for the classification. There is a classification of entrepreneurial members in the family (the data covers the entire sample of parents starting a business), and there is no classification of entrepreneurial members into another category. It has a certain reference value and significance for entrepreneurship education. This means that there is a significant difference between college students with "family background" and college students with "no family background" in terms of college students 'entrepreneurship education. In comparison, University clubs with "family background" are willing to receive more entrepreneurial education than those with "no family background". They also have stronger entrepreneurial intentions and more entrepreneurial competence. They are more serious and proactive in learning entrepreneurial education. More likely to have a learning effect.

\section{Expert interview method}

Based on the current situation of college students 'entrepreneurship education, we interviewed several entrepreneurship experts.

Entrepreneurship education should be aimed at different students to carry out different entrepreneurship education. As a result, the demand for talents in various fields and the personality characteristics of college students should be carried out in stages or in layers to better highlight and change college students 'understanding of entrepreneurship. To increase entrepreneurial knowledge to help college students form and improve entrepreneurial intentions, thus improving the effectiveness and practicality of entrepreneurial education, and thus enhance students 'entrepreneurial learning enthusiasm. In entrepreneurship education, we should have a significant positive impact on the entrepreneurial intentions of college 
students. After studying, college students should actively participate in entrepreneurial projects, and they can effectively exert their advantages and improve the success rate of entrepreneurial projects. Entrepreneurship education should also give full play to the important role of students 'sense of self-efficacy in the entrepreneurial process, especially having a family entrepreneurial background (such as the entrepreneurial role of entrepreneurs and parents in the family, individual previous entrepreneurial experience), You can introduce your own examples into the classroom of entrepreneurship education. You can say this out loud, make entrepreneurship education classroom more attractive, and it will also lead to higher entrepreneurial intentions among students, and you are more willing to join entrepreneurship class. In entrepreneurship education, we should consider the influence of the individual characteristics of college students on entrepreneurial intentions and entrepreneurial competence. If we can achieve layered teaching or cooperation between college students with different personality characteristics to carry out practical teaching, we believe that it will benefit greatly.

Innovation and entrepreneurship of college students and teaching integration is a successful development model. For students, this is not only to build a better entrepreneurial platform for students, but also to create more entrepreneurial learning opportunities and future employment opportunities for students. For the school, it is not only conducive to improving the quality of training talents and enhancing the social competitiveness of students, but also conducive to better University innovation and entrepreneurship education, entrepreneurship base construction and promotion of college students 'independent entrepreneurship work and employment work.

\section{Conclusion}

This study is a research proposal, and we just state for the research concept. In the next, we will develop a theoretic model, collect and analyze related data, and finish the interview with experts. In the contribution, our research results will provide a valuable suggestion to colleges, and help them improve the entrepreneurship education, and avoid the affecting of personality traits, and further ensure training results of students.

\section{Acknowledgement}

This work was supported by the research project of Human Resources and Social Security of the China, under Grant 2018059.

\section{References}

[1] Matlay H. The Impact of Entrepreneurship Education on Entrepreneurial Outcomes. Journal of Small Business and Enterprise Development, 2008, 15(2): 382-396.

[2] Francisco Liñán, Juan Carlos Rodríguez Cohard, José M. Rueda Cantuche, Factors Affecting Entrepreneurial Intention Levels: a Role for Education. International Entrepreneurship and Management Journal, 2011(2): 195-218.

[3] Bechard, J.P., Toulouse, J.M.. Entrepreneurship and Education: View Point from Education. Journal of Small Business and Enterprise, 1991 (1): 3-13.

[4] Cooper, S. Y., Lucas, W. A.. Developing Entrepreneurial
Self-efficacy and Intentions: Lessons from Two Programmes. Paper presented at the Proceedings of the 52nd ICSB World Conference, 2007.

[5] Fayolle, A., De George, J. M.. Attitudes, Intentions, and Behaviour: New approaches to Evaluating Entrepreneurship Education. In A. Fayolle \& H. Klandt (Eds.), International Entrepreneurship Education. Issues and Newness (pp.74-89). Cheltenham: Edward Elgar. 2006.

[6] Kolvereid, L., Isaksen, E.. New Business Startup and Subsequent Entry into Self-Employment. Journal of Business Venturing, 2006(6): 866-885

[7] John W Malone. Shining a New Light on Organizational Change: Improving Self-Efficacy through Coaching. Organization Development Journal, 2001(2): 27-36.

[8] Sara E Rimm-Kaufman, Brook E Sawyer.. Primary-Grade Teachers' Self-Efficacy Beliefs, Attitudes toward Teaching, and Discipline and Teaching Practice Priorities in Relation to the Responsive Classroom Approach. The Elementary School Journal, 2004(4): 321-340.

[9] Mueller, S. L. Gender Gaps in Potential for Entrepreneurship across Countries and Cultures. Journal of Developmental Entrepreneurship, 2004(3): 199-220.

[10] Heilman, M.E.. Description and Prescription: How Gender Stereotypes Prevent Women's Ascent up the Organizational Ladder. Journal of Social Issues, 2001(4):657-674.

[11] Li Liang, Li Liuxiaoli, Zhang Guoli. "Internet +" era of college students 'entrepreneurial ability cultivation exploration. Science and Education Language Exchange(mid-issue), 2016, (2): 41-42.

[12] Chen, C. C., Greene, P G, Crick, A.. Does Entrepreneurial Self-Efficacy Distinguish Entrepreneurs from Managers. Journal of Business Venturing, 1998 (3): 295-316.

[13] De Noble, A. F., Jung, D. I., Ehrlich, S B.. Entrepreneurial Self-Efficacy: The Development of a Measure and its Relationship to Entrepreneurial Action, in Reynolds, R D, et al (Eds). Frontiers of entrepreneurship research. Waltham. MA: Pand R Publication Inc.,1999: 73-78. 
Educational Innovations and Applications- Tijus, Meen, Chang ISBN: 978-981-14-2064-1 